\title{
Sister chromatid exchange: A possible approach to characterize familial breast cancer patients
}

\author{
IVANA DE PASCALIS ${ }^{1}$, BRUNELLA PILATO ${ }^{2}$, ANNALISA MAZZOTTA ${ }^{1}$, TERESA STEFANIA DELL'ENDICE ${ }^{1}$, \\ VINCENZA RUBINI $^{3}$, GIOVANNI SIMONE $^{3}$, ANGELO PARADISO $^{4}$, VINCENZO AIELLO $^{5}$ and ANITA MANGIA ${ }^{1}$ \\ ${ }^{1}$ Functional Biomorphology Laboratory, ${ }^{2}$ Molecular Genetics Laboratory, ${ }^{3}$ Pathology Department, \\ ${ }^{4}$ Experimental Medical Oncology, NCRC, IRCSS Istituto Tumori ‘Giovanni Paolo II', Bari; \\ ${ }^{5}$ Medical Genetics, University of Ferrara, Ferrara, Italy
}

Received June 18, 2014; Accepted September 17, 2014

DOI: $10.3892 /$ or.2014.3628

\begin{abstract}
Sister chromatid exchange (SCE) frequency is widely used as an indicator of spontaneous chromosome instability. We investigated SCE frequency in the peripheral blood lymphocytes of familial and sporadic breast cancer (BC) patients from the Apulian Caucasian Population. Eighty-one patients were enrolled: 22 with familial history and 59 sporadic patients. Eleven familial patients had an 'increased risk' of $B R C A$ gene mutation (BRCAPro $\geq 10 \%$ ) and were candidates for $B R C A 1$ and BRCA2 mutation analysis. For these reasons, we stratified the 22 familial BC patients in two group: 'lowrisk' ( $n=11)$ and 'high-risk' $(n=11)$ patients for BRCA gene mutations. Two of these 11 'high-risk' patients (18\%) had pathogenic mutations in the BRCA2 gene. The subjects were not cigarette smokers or alcohol or drug users, and had no genetic disorders or chronic diseases affecting the family. Our results showed a significant increase in SCE frequency in the familial $(5.305 \pm 1.088 /$ metaphase $)(\mathrm{P}<0.0001)$ and the sporadic patients $(3.943 \pm 0.552)(\mathrm{P}<0.0001)$ compared to the controls (3.197 \pm 0.649$)$. We found that the SCE frequency was always significantly higher in familial than in sporadic patients, regardless of their clinicopathological characteristics. Moreover, we observed that the frequency of SCE in BRCA2 mutation carrier patients was higher compared to patients without mutations in $B R C A 1 / 2$ genes. These findings highlight an intrinsic genomic instability in familial patients, and we suggest that SCE frequency may be used as a biomarker to better characterize familial $\mathrm{BC}$.
\end{abstract}

Correspondence to: Dr Anita Mangia, Functional Biomorphology Laboratory, NCRC, IRCSS Istituto Tumori 'Giovanni Paolo II', Viale Orazio Flacco 65, 70124 Bari, Italy

E-mail: a.mangia@oncologico.bari.it

Key words: sister chromatid exchange, familial breast cancer, $B R C A$ genes, sporadic breast cancer

\section{Introduction}

Breast cancer (BC), the most frequent carcinoma in women, is a multifactorial disease occurring as a result of environmental and heritable factors. It is estimated that $5-10 \%$ of all breast carcinomas are inherited, whereas the remaining 90-95\% are sporadic carcinomas. BRCA1 and BRCA2 genes are responsible for $3-8 \%$ of all $\mathrm{BCs}$ and for $15-20 \%$ of familial cases (1), and because these genes are involved in maintaining genome integrity the complete loss of function of encoded proteins leads to genomic instability $(2,3)$. Increased genetic susceptibility could be associated with genomic instability, which could lead to chromosomal breakage. Sister chromatid exchange (SCE) is an error-free recombination mechanism, defined as a symmetrical exchange between portions of apparently homologous sister chromatids (4). Although little is known about its molecular basis, these exchanges presumably involve DNA breakage and subsequent reunion of newly synthesized DNA chains during replication $(5,6)$. An increase in SCE frequency is found in patients with various types of cancers, such as uterine cervix (7) ovary (8), prostate (9), nasopharynx (10) and BC (11). Regarding BC, Roy et al reported increased spontaneity of SCE frequency in hereditary BC patients compared to their healthy relatives (12). Conversely, Cefle et al (13) found no difference in SCE frequency between patients with BC and their first-degree relatives. Finally, in an observational study, Aristei et al (14) showed an increase in SCE frequency in early-stage BC patients compared to controls, with no significant differences in SCE in patients with or without a family history of cancer. In the present study, we evaluated the SCE frequency in the peripheral blood lymphocytes of familial and sporadic BC patients from the Apulian Caucasian population in order to verify whether a difference exists among these groups. This is the first study to investigate SCE frequency in this specific population.

\section{Materials and methods}

Patient characteristics. SCE frequency was investigated in 22 familial and 59 sporadic female patients with a first diagnosis of primary BC, and compared with 20 healthy control 
women with no history of any cancer for the last three generations. The study was approved by the Institutional Review Board of our Institute. Before undergoing routine surgery, all patients signed an informed consent form authorizing the Institute to utilize their blood sample for research purposes according to ethical standards.

All the subjects came from the Apulian Caucasian population, and none were cigarette smokers, or alcohol or drug users. Furthermore, no subject had genetic disorders or chronic diseases affecting the family. This information was controlled by careful medical interviews. We stratified the 22 familial BC patients in two group: 'low-risk' $(n=11)$ and 'high-risk' $(n=11)$ patients for $B R C A$ gene mutations. Eleven patients with a familial history of BC and with a BRCAPro value $\geq 10 \%$ were eligible for the genetic counseling program, and were screened for mutations in the $B R C A 1$ and $B R C A 2$ genes as previously described $(1,15)$. Tumor characteristics including tumor size, nodal status, tumor grade, estrogen receptor (ER), progesterone receptor (PR), proliferative activity (MIB1) and human epidermal growth factor receptor 2 (HER2) were provided by the Pathology Department of our Institute (Table I).

The cut-off value for ER and PR was $10 \%$. Tumors with ER or PR expression were scored as positive when nuclear staining was present in $>10 \%$ of tumor cells and scored negative when $\leq 10 \%$ of the tumor cells had nuclear staining. Cases with an MIB1 index $>20 \%$ were considered high proliferating tumors. The MIB1 cut-off represents the median value of the scores relative to all $\mathrm{BC}$ samples analyzed during the last five years at our Institute.

HER2 was scored as $0,1+, 2+$ or $3+$ using a monoclonal antibody (MoAb clone CB11; Novocastra Laboratories, Ltd., Newcastle, UK), in accordance with the HercepTest scoring system (Food and Drug Administration accepted): 0, no membranous immunoreactivity or $<10 \%$ of cells reactive; $1+$, incomplete membranous reactivity in $>10 \%$ of cells; $2+,>10 \%$ of cells with weak to moderate complete membranous reactivity; and $3+$, strong and complete membranous reactivity in $>10 \%$ of cells. Cytoplasmic immunoreactivity was ignored. Cases scoring 0 and 1+ were classified as negative. HER2 was considered to be positive if immunostaining was $3+$ or if a $2+$ result showed gene amplification by fluorescence in situ hybridization (FISH). In FISH analyses, each copy of the HER2 gene and its centromere 17 (CEP17) reference were counted. The interpretation followed the criteria of the ASCO/CAP guidelines for HER2 immunohistochemistry interpretation for BC (16): positive if the HER2/CEP17 ratio was $>2.2$.

SCE assay. Venous blood from 81 BC patients and 20 healthy controls was preserved in heparinized tubes. For SCE analyses, blood cultures were prepared from blood samples in accordance with the standard protocol on peripheral blood cultures. 5-Bromo-2'-deoxyuridine (BrdU; Sigma, St. Louis, MO, USA) was added at a final concentration of $10 \mu \mathrm{g} / \mathrm{ml}$ at the 24th hour and incubated for $72 \mathrm{~h}$ (4). The slides were prepared in accordance with standard methods and were stained with the fluorescence-plus-Giemsa technique (17). The slides were incubated for $15 \mathrm{~min}$ in a bisbenzimide Hoechst 33258 solution $(5 \mu \mathrm{g} / \mathrm{ml})$ (bisbenzimide; Histoline Laboratories S.R.L., Milan), and then washed with distilled water. The slides were

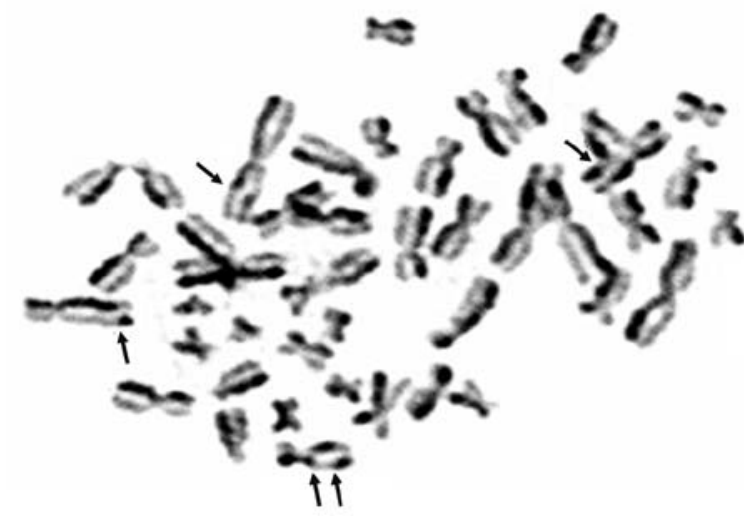

Figure 1. Typical chromosomes in metaphase. The image shows sister chromatid exchange (SCE) in peripheral blood lymphocytes of the breast cancer patients (marked by black arrows).

then incubated in fresh phosphate-buffered water under a UV light source for $1 \mathrm{~h}$. The slides were washed again, incubated for $10 \mathrm{~min}$ in preheated $2 \mathrm{X}$ saline-sodium citrate solution at $56^{\circ} \mathrm{C}$ in a water-bath, and, after further rinsing, stained with 10X phosphate-buffered Giemsa solution.

For each subject 50 metaphases were examined by two observers, who had no knowledge of the patient information (Fig. 1). Every metaphase was scored for SCEs, and the individual mean value \pm standard deviation/cell was calculated. SCE baseline values of the familial group were compared with those of the sporadic patients and with those of the control group.

Statistical analysis. The statistical association of mean SCE frequency with clinicopathologic characteristics was assessed using the Fisher's exact test and the Student's t-test. The parametric one-way analysis of variance and the post hoc Bonferroni's multiple comparison tests were carried out to compare the mean frequency of SCEs per cell among the familial, sporadic and control groups. All statistical differences were considered significant at the level of $\mathrm{P}<0.05$. Statistical analyses were performed using SPSS 14.0 statistical software (SPSS, Inc., Chicago IL, USA).

\section{Results}

The mean value of the SCE frequency in familial and sporadic patients was $5.305 \pm 1.088$ and $3.943 \pm 0.552$, respectively, whereas it was $3.197 \pm 0.649$ in the control group. Statistical analysis demonstrated that the SCE frequency in the familial patients was significantly higher than that in both sporadic patients $(\mathrm{P}<0.0001)$ and healthy controls $(\mathrm{P}<0.0001)$. Moreover, SCE frequency in the sporadic patients was significantly higher compared to that in the control group $(\mathrm{P}<0.0001)$ (Fig. 2).

When comparing the mean SCE frequency value of familial and sporadic patients with their clinicopathological characteristics, we found that SCE frequency was always higher in familial than in sporadic patients (Table I).

The mean ages of familial and sporadic patients and the control group were 49, 57 and 37 years, respectively. No significant association between the mean value of SCE frequencies and the age of all subjects analyzed was found. 
Table I. Clinicopathological characteristics and mean SCE in familial and sporadic breast cancer patients.

\begin{tabular}{|c|c|c|c|c|}
\hline \multirow[b]{2}{*}{ Characteristics } & \multicolumn{2}{|c|}{ Familial n=22 } & \multicolumn{2}{|c|}{ Sporadic $n=59$} \\
\hline & No. of patients $(\%)$ & Mean SCE & No. of patients (\%) & Mean SCE \\
\hline \multicolumn{5}{|l|}{ Age (years) } \\
\hline$\leq 55$ & $17(77)$ & 5.5 & $27(46)$ & 4.0 \\
\hline$>55$ & $5(23)$ & 4.8 & $32(54)$ & 3.9 \\
\hline \multicolumn{5}{|l|}{ Tumor size (cm) } \\
\hline$\leq 2$ & $12(55)$ & 5.2 & $27(46)$ & 4.0 \\
\hline$>2$ & $10(45)$ & 5.4 & $32(54)$ & 3.4 \\
\hline \multicolumn{5}{|l|}{ Nodal status } \\
\hline Negative & $17(81)$ & 5.4 & $32(54)$ & 3.9 \\
\hline Positive & 4 (19) & 5.3 & $27(46)$ & 3.9 \\
\hline \multicolumn{5}{|l|}{ Tumor grade } \\
\hline $1-2$ & $15(68)$ & 5.4 & $30(51)$ & 3.9 \\
\hline 3 & $7(32)$ & 5.1 & $29(49)$ & 3.9 \\
\hline \multicolumn{5}{|l|}{ ER } \\
\hline Negative $(\leq 10 \%)$ & $6(27)$ & 5.1 & $15(25)$ & 4.0 \\
\hline Positive (>10\%) & $16(73)$ & 5.4 & $44(75)$ & 3.9 \\
\hline \multicolumn{5}{|l|}{ PR } \\
\hline Negative $(\leq 10 \%)$ & $12(55)$ & 5.3 & $19(32)$ & 4.0 \\
\hline Positive (>10\%) & $10(45)$ & 5.3 & $40(68)$ & 3.9 \\
\hline \multicolumn{5}{|l|}{ MIB1 } \\
\hline Negative $(\leq 20 \%)$ & $16(73)$ & 5.3 & $38(64)$ & 3.9 \\
\hline Positive $(>20 \%)$ & $6(27)$ & 5.0 & $21(36)$ & 4.1 \\
\hline \multicolumn{5}{|l|}{$\mathrm{HER}^{\mathrm{a}}{ }^{\mathrm{a}}$} \\
\hline Negative $(0,1+)$ & $14(82)$ & 5.4 & $37(67)$ & 3.9 \\
\hline Positive $(3+)$ & $3(18)$ & 4.8 & $18(33)$ & 3.9 \\
\hline
\end{tabular}

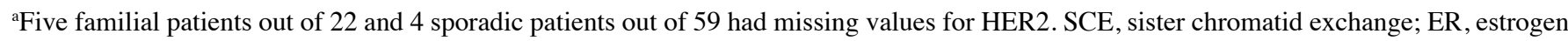
receptor; PR, progesterone receptor; MIB1, labeling index; HER2, human epidermal growth factor receptor 2.

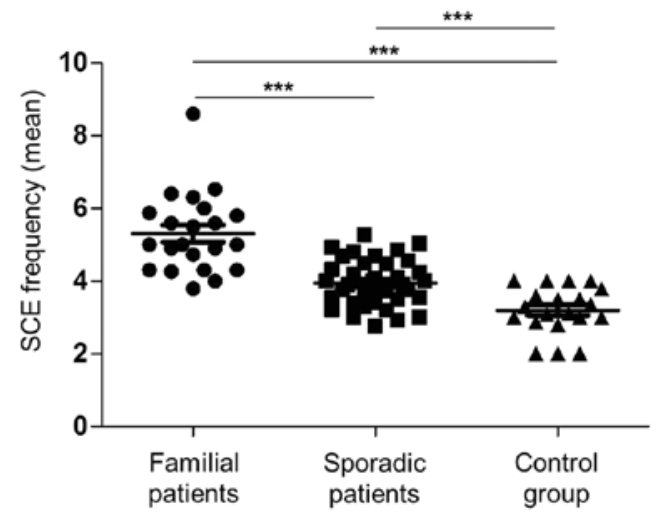

Figure 2. The sister chromatid exchange (SCE) frequency in breast cancer patients and the control group. The frequency was significantly increased in 22 familial patients $(5.305 \pm 1.088)$ compared to 59 sporadic patients $(3.943 \pm 0.552)$ and 20 healthy subjects in the control group $(3.197 \pm 0.649)$. Data are expressed as mean \pm standard deviation/metaphase; ${ }^{* * *} \mathrm{P}<0.0001$.

In accordance with the statistical analysis, no significant difference in SCE frequency between low-risk and high-risk patients was observed with respect to the BRCAPro value (cut-off $\geq 10 \%$ ). Furthermore, we correlated SCE frequency with the $B R C A$ mutational status of two patients (18\%) with two pathogenic mutations in the BRCA2 gene: 2029 delCTTAT and 2049delTC. The SCE frequency was higher compared to patients without $B R C A 2$ mutations (data not shown).

\section{Discussion}

The aim of this preliminary study was to investigate if a difference in SCE frequency existed between familial and sporadic Caucasian BC patients from the Apulia Region. We used the SCE assay, a classic cytomolecular technique which provides an easy and accurate index to monitor DNA damage and DNA repair status. The use of lymphocytes is based on the assumption of a hypothetical association between the presence of chromosomal damage both in lymphocytes and in tumor cells (18). Even though several studies have investigated SCE frequency in BC patients (11-14), this is the first report to analyze SCE in heredo-familial BC patients as compared to sporadic patients in a Caucasian population from Southern 
Italy. None of the patients or healthy controls were cigarette smokers nor alcohol or drug users, as several authors have reported an increase in the mean value of SCE due to lifestyle factors $(19,20)$.

In the present study, a significant increase in the frequency of SCE was observed in familial compared to sporadic patients, hypothesizing an increased genome susceptibility as previously reported (13). However, in our series of BC patients, we found an SCE frequency lower than that of other studies $(13,21)$. We believe that the frequency of SCE of the $\mathrm{BC}$ patients from the Apulia Caucasian population is different than that in other populations. Further studies are needed to confirm our hypothesis. Furthermore, our results showed that clinicopathological characteristics of familial and sporadic tumors did not correlate with SCE frequency (14). SCE was always higher in the familial than that in the sporadic tumors but the difference did not achieve statistical significance. Lack of association could be due to the small number of patients included in the analysis. This reflects the difficulty in enrolling untreated non-smoking patients; this is necessary to avoid confounding effects that could influence the sensitive parameters being investigated in this study.

Considering that SCE showed a higher value in familial patients, we suggest that SCE could be a biomarker independent of the clinicopathological characteristics used in clinical practice to characterize this type of BC phenotype.

Since age and genomic instability are associated with failure of DNA repair and accumulation of DNA damage in the genome, many authors have evaluated the association between SCE frequency and age, but data in the literature are controversial $(4,14,19,22-24)$. In accordance with other studies, we found no correlation between age and SCE frequency, either in familial or in sporadic patients $(4,14)$.

It is known that $B R C A 1$ and $B R C A 2$ are required for the maintenance of genomic integrity and that $B R C A$ gene products are necessary for the control of faithful homologous recombination between sister chromatids in response to DNA damage (2). Our statistical analysis demonstrated no significant difference in SCE frequency between 'low-risk and high-risk' patients. On the other hand, Trenz et al (25) found no significant difference between the SCE of patients carrying a BRCAI mutation and healthy donors without a family history of cancer.

In the present study, we investigated the probable relationship between $B R C A$ mutations and the corresponding values of SCE. We found an increase in SCE frequency in patients with heterozygous germline mutations in BRCA2. This finding is in agreement with a study by Kim et al (26), which suggests a role of the BRCA2 mutation in the increase of SCE, as if the reduction in $B R C A 2$ gene dosage decreases the ability of cells to maintain chromosome stability compared to wild-type level. In fact, $B R C A 2$ is involved in DNA repair, and the loss of function of this protein leads to an increase in genomic instability.

In conclusion, in Caucasian patients from the Apulia Region of Southern Italy with a family history of BC, we showed a significant increase in SCE frequency, in particular in BRCA mutation carriers. We suggest that SCE frequency may be used as a biomarker to better characterize familial $\mathrm{BC}$, and we hypothesize that the $B R C A$ gene could be involved in the molecular mechanism of SCE. Further investigation of the correlation between SCE and BRCA1/BRCA2 mutation carriers and subsequent evaluation of SCE as a valuable marker for cancer prediction in high-risk relatives are warranted.

\section{Acknowledgements}

We thank Patrizia Chiarappa and Vanessa Desantis for management of the clinical samples. The authors also thank Caroline Oakley for language revision (Scientific Direction).

\section{References}

1. Pilato B, Martinucci M, Danza K, Pinto R, Petriella D, Lacalamita R, Bruno M, Lambo R, D'Amico C, Paradiso A and Tommasi S: Mutations and polymorphic BRCA variants transmission in breast cancer familial members. Breast Cancer Res Treat 125: 651-657, 2011.

2. Levin B, Lech D and Friedenson B: Evidence that BRCA1- or BRCA2-associated cancers are not inevitable. Mol Med 18: 1327-1337, 2012.

3. O'Donovan PJ and Livingston DM: BRCA1 and BRCA2: breast/ ovarian cancer susceptibility gene products and participants in DNA double-strand break repair. Carcinogenesis 31: 961-967, 2010.

4. Tekcan A,Elbistan M and Ulusoy AN: Sister chromatid exchanges in breast cancer patients who underwent chemotherapy. J Toxicol Sci 37: 235-243, 2012.

5. Conrad S, Künzel J and Löbrich M: Sister chromatid exchanges occur in G2-irradiated cells. Cell Cycle 10: 222-228, 2011.

6. White JS, Choi S and Bakkenist CJ: Transient ATM kinase inhibition disrupts DNA damage-induced sister chromatid exchange. Sci Signal 3: ra44, 2010.

7. Bozsakyova E, Wsolova L and Chalupa I: Spontaneous and gamma-ray-induced sister chromatid exchanges in patients with carcinoma of cervix uteri. Int J Radiat Biol 81: 177-185, 2005

8. Baltaci V, Kayikçioğlu F, Alpas I, Zeyneloğlu H and Haberal A Sister chromatid exchange rate and alkaline comet assay scores in patients with ovarian cancer. Gynecol Oncol 84: 62-66, 2002.

9. Dhillon VS and Dhillon IK: Chromosome aberrations and sister chromatid exchange studies in patients with prostate cancer: possible evidence of chromosome instability. Cancer Genet Cytogenet 100: 143-147, 1998.

10. Wang LY, Lai MS, Huang SJ, Hsieh CY, Hsu MM and Chen CJ: Increased sister chromatid exchange frequency in peripheral lymphocytes of nasopharyngeal carcinoma and cervical cancer patients. Anticancer Res 14: 105-107, 1994.

11. Dhillon VS, Bhasker R, Kler RS and Husain SA: Sister chromatid exchange (SCE) studies in breast cancer patients: a follow-up study. Cancer Genet Cytogenet 80: 115-117, 1995.

12. Roy SK, Trivedi AH, Bakshi SR, Patel RK, Shukla PH, Patel SJ Bhatavdekar JM, Patel DD and Shah PM: Spontaneous chromosomal instability in breast cancer families. Cancer Genet Cytogenet 118: 52-56, 2000.

13. Cefle K, Ucur A, Guney N, Ozturk S, Palanduz S, Tas F, Asoglu O, Bayrak A, Muslumanoglu $\mathrm{M}$ and Aydiner A: Increased sister chromatid exchange frequency in young women with breast cancer and in their first-degree relatives. Cancer Genet Cytogenet 171: 65-67, 2006

14. Aristei C, Stracci F, Guerrieri P, Anselmo P, Armellini R, Rulli A, Barberini F, Latini P and Menghini AR: Frequency of sister chromatid exchanges and micronuclei monitored over time in patients with early-stage breast cancer: results of an observational study. Cancer Genet Cytogenet 192: 24-29, 2009.

15. Mangia A, Chiriatti A, Tommasi S, Menolascina F, Petroni S Zito FA, Simone G, Schittulli F and Paradiso A: BRCA1 expression and molecular alterations in familial breast cancer. Histol Histopathol 24: 69-76, 2009.

16. Wolff AC, Hammond ME, Schwartz JN, Hagerty KL, Allred DC, Cote RJ, Dowsett M, Fitzgibbons PL, Hanna WM, Langer A, McShane LM, Paik S, Pegram MD, Perez EA, Press MF, Rhodes A, Sturgeon C, Taube SE, Tubbs R, Vance GH, van de Vijver M, Wheeler TM and Hayes DF: American Society of Clinical Oncology/College of American Pathologists guideline recommendations for human epidermal growth factor receptor 2 testing in breast cancer. J Clin Oncol 25: 118-145, 2007.

17. Perry P and Wolff S: New Giemsa method for the differential staining of sister chromatids. Nature 251: 156-158, 1974. 
18. Hagmar L, Bonassi S, Stromberg U, Brogger A, Knudsen LE, Norppa $\mathrm{H}$ and Reuterwall C: Chromosomal aberrations in lymphocytes predict human cancer: a report from the European Study Group on Cytogenetic Biomarkers and Health (ESCH). Cancer Res 58: 4117-4121, 1998.

19. Barale R, Chelotti L, Davini T, Del Ry S, Andreassi MG, Ballardin M, Bulleri M, He J, Baldacci S, Di Pede F, Gemignani F and Landi S: Sister chromatid exchange and micronucleus frequency in human lymphocytes of 1,650 subjects in an Italian population: II. Contribution of sex, age, and lifestyle. Environ Mol Mutagen 31: 228-242, 1998.

20. Kumar JV, Saraswathi T, Ranganathan K, Umadevi K, Joshua E and Rooban T: Sister chromatid exchanges in smokers and smokers with alcohol habit. J Oral Maxillofac Pathol 16: 338-342, 2012.

21. Celik DA, Koşar PA, Ozçelik N and Eroğlu E: Cytogenetic finding of breast cancer cases and in their first-degree relatives. J Breast Cancer 16: 285-290, 2013.
22. Ben Salah G, Kamoun H, Rebai A, Ben Youssef A, Ayadi H, Belghith-Mahfoudh N, Fourati A, Ayadi H and Fakhfakh F: Sister chromatid exchange (SCE) and high-frequency cells (HFC) in peripheral blood lymphocytes of healthy Tunisian smokers. Mutat Res 719: 1-6, 2011.

23. Bernardes de Jesus B and Blasco MA: Telomerase at the intersection of cancer and aging. Trends Genet 29: 513-520, 2013.

24. Jacobs PA, Maloney V, Cooke R, Crolla JA, Ashworth A and Swerdlow AJ: Male breast cancer, age and sex chromosome aneuploidy. Br J Cancer 108: 959-963, 2013.

25. Trenz K, Lugowski S, Jahrsdörfer U, Jainta S, Vogel W and Speit G: Enhanced sensitivity of peripheral blood lymphocytes from women carrying a BRCA1 mutation towards the mutagenic effects of various cytostatics. Mutat Res 544: 279-288, 2003.

26. Kim MK, Zitzmann S, Westermann F, Arnold K, Brouwers S, Schwab M and Savelyeva L: Increased rates of spontaneous sister chromatid exchange in lymphocytes of BRCA2 $2^{+/}$carriers of familial breast cancer clusters. Cancer Lett 210: 85-94, 2004. 